\title{
Iron metabolism in the pathogenesis of iron-induced kidney injury
}

\author{
A. M. F. Martines, R. Masereeuw, H. Tjalsma, J. G. Hoenderop, J. F. M. Wetzels and D. W. Swinkels
}

\begin{abstract}
In the past 8 years, there has been renewed interest in the role of iron in both acute kidney injury (AKI) and chronic kidney disease (CKD). In patients with kidney diseases, renal tubules are exposed to a high concentration of iron owing to increased glomerular filtration of iron and iron-containing proteins, including haemoglobin, transferrin and neutrophil gelatinase-associated lipocalin (NGAL). Levels of intracellular catalytic iron may increase when glomerular and renal tubular cells are injured. Reducing the excessive luminal or intracellular levels of iron in the kidney could be a promising approach to treat AKI and CKD. Understanding the role of iron in kidney injury and as a therapeutic target requires insight into the mechanisms of iron metabolism in the kidney, the role of endogenous proteins involved in iron chelation and transport, including hepcidin, NGAL, the NGAL receptor and divalent metal transporter 1, and iron-induced toxic effects. This Review summarizes emerging knowledge, which suggests that complex mechanisms of iron metabolism exist in the kidney, modulated directly or indirectly by cellular iron content, inflammation, ischaemia and oxidative stress. The potential exists for prevention and treatment of iron-induced kidney injury by customized iron removal or relocation, aided by detailed insight into the underlying pathological mechanisms.
\end{abstract}

Martines, A. M. F. et al. Nat. Rev. Nephrol. advance online publication 14 May 2013; doi:10.1038/nrneph.2013.98

\section{Introduction}

Iron is an indispensable component of haemoglobin and myoglobin, ${ }^{1,2}$ proteins that have key roles in the preservation of life. However, excessive levels of iron have toxic effects due to the ability of iron to catalyse the generation and propagation of reactive oxygen species. ${ }^{1,3}$ Moreover, to the best of our knowledge, actively regulated iron excretion has not been reported. Thus, iron deficiency, displacement and overload can all have serious consequences for an organism. ${ }^{4}$

Iron metabolism is regulated systemically by the hepatic hormone, hepcidin, and its interaction with the cellular iron exporter, ferroportin. Hepcidin is mostly produced and secreted by the liver, although it can also be produced in proximal and distal regions of the nephron (Table 1), ${ }^{5,6}$ and might have a role in iron metabolism in the kidney. ${ }^{7}$ Hepcidin regulates both the absorption of dietary iron and the distribution of iron throughout the body by binding to and inducing degradation of the iron exporter, ferroportin, on the basolateral membrane of enterocytes and plasma membrane of macrophages. Hepcidin has also been reported to bind to free iron, and at high concentrations, this hormone has intrinsic antibacterial activity, causing bacterial cell lysis. ${ }^{5}$ This antibacterial activity could result in the sequestration of iron from pathogenic bacteria, thereby preventing bacterial proliferation. In addition, the synthesis of hepcidin is regulated by various stimuli,

Competing interests

The authors declare no competing interests. including inflammation and oxidative stress. ${ }^{5}$ The hepcidin peptide has been identified as a potential prognostic marker in patients who develop acute kidney injury (AKI) after cardiopulmonary bypass surgery. ${ }^{8-10}$

Intracellular levels of iron are controlled by iron regulatory proteins (IRPs) that bind to iron-responsiveelements (IREs) in mRNA. ${ }^{2}$ The IRP-IRE system affects post-transcriptional regulation of iron storage capacity. For example, in iron-deprived conditions, IRPs bind with high affinity to IREs in the 3 ' untranslated region (UTR) of transferrin receptor protein 1 (TFRC) and divalent metal transporter 1 (DMT-1, also known as natural resistance-associated macrophage protein 2) mRNA, and to the 5' UTR of ferroportin, ferritin heavy chain and ferritin light chain mRNA. This binding increases the levels of cellular free iron and transferrinbound iron and at the same time inhibits iron storage in ferritin and iron export by inhibition of de novo ferritin synthesis and ferroportin-mediated export. By contrast, in iron-rich conditions, IRP binding affinity with IREs is low, thereby favouring the opposite effects. In this way, IRPs induce iron uptake and promote cellular iron retention in iron-deprived conditions, and decrease iron uptake and stimulate the release of intracellular iron in iron-rich conditions. ${ }^{2}$

The interest of nephrologists in iron disorders has historically been limited, since no reports have described iron overload in the kidney in patients with HFErelated hereditary haemochromatosis, ${ }^{11}$ a condition in which increased intestinal absorption of iron results
Department of Laboratory Medicine, Laboratory of Genetic Endocrine and Metabolic diseases (A. M. F. Martines, H. Tjalsma,

D. W. Swinkels), Department of Pharmacology and Toxicology (R. Masereeuw), Department of Physiology (J. G. Hoenderop), Department of Nephrology, Radboud University Medical Centre, Geert Grooteplein-Zuid 10, 6525 GA Nijmegen, the Netherlands (J. F. M. Wetzels).

Correspondence to:

D. W. Swinkels

d.swinkels@

labgk.umen.nl 


\section{Key points}

- Iron content in the kidneys is increased in patients with chronic kidney disease or acute kidney injury, and is associated with proteinuria, haematuria or haemoglobinuria

- Increased local exposure to iron in the kidney may have a role in causing acute kidney injury, development and progression of kidney disease and in causing end-stage renal disease

- Decreasing the excessive iron in the kidneys may be a novel approach to treat acute kidney injury and chronic kidney disease

- The kidneys express many proteins that are involved in iron metabolism and transport

- The precise role and regulation of many proteins involved in renal iron metabolism and iron-induced kidney injury is poorly understood

in systemic iron overload. ${ }^{12,13}$ However, a role for iron in kidney disease was proposed more than two decades ago $^{3,14,15}$ and interest in iron-mediated kidney injury has increased with discovery that proteins such as hepcidin and neutrophil gelatinase-associated lipocalin (NGAL) have key roles in iron metabolism. ${ }^{3,5,16-20}$ Indeed, NGAL shares many features with hepcidin. NGAL is produced by macrophages, as well as in proximal and distal renal tubules and is present in serum. NGAL also has wellknown iron-binding and antimicrobial properties. ${ }^{5,21}$ Expression of NGAL is recognized as an early marker of AKI, ${ }^{19-22}$ and experimental evidence suggests that this protein might protect the kidney against AKI, for example that caused by ischaemia-reperfusion injury. ${ }^{19}$ By contrast, NGAL might contribute to the progression of chronic kidney disease (CKD), ${ }^{6,22}$ possibly as a result of proinflammatory properties or function in iron mobilization. ${ }^{21}$ The mostly incomplete evidence on the roles of hepcidin, NGAL and iron itself in kidney injury call for a review of data on this emerging topic.

In this Review, we summarize current knowledge about the physiology of iron metabolism in the kidney, delineate the potential role of iron in kidney injury and discuss possible underlying pathological mechanisms that contribute to altered iron metabolism in the kidney and catalytic iron-induced kidney injury. This knowledge may pave the way for novel treatments for common progressive kidney diseases, including proteinuric and haematuric kidney injury. We hypothesize that treatments for kidney injury will incorporate manipulation of iron metabolism in the kidney and predict that extensive research efforts will be directed toward this goal in the near future. ${ }^{23-25}$

\section{Iron metabolism in the kidney}

Iron transport and regulation in the kidney involves an array of processes and proteins (Table 1, Figure 1), which underscores the complexity of these processes.

\section{Glomerular filtration of iron}

Under physiological conditions, circulating iron enters the renal tubular lumen via the glomerulus. ${ }^{11,26}$ Circulating iron is predominantly bound to transferrin and to a lesser extent, other filterable iron-binding proteins, including NGAL, lactoferrin, albumin, haemoglobin, myoglobin and hepcidin. 5,11-13,20,27-29 The proportion of circulating iron filtered by the human kidney is unknown. If we assume that all iron in serum is bound to transferrin and that no reabsorption of transferrin occurs in the proximal tubules, the rate of iron filtration can be calculated as $0.009 \mathrm{mg}$ per day. ${ }^{30}$ This value is probably an underestimate, since the possibility of transferrin reabsorption via the NGAL receptor, (NGALR), in the distal convoluted tubules and collecting ducts is not taken into account. We calculate, using data on iron filtration in the rat, that the rate of iron filtration can be up to $15 \mathrm{mg}$ per day. ${ }^{11,31}$ This value is probably an overestimate, however, because the renal micropuncture method ${ }^{11}$ used to collect the filtrate might result in contamination of the sample with blood. Moreover, the permeability of the glomerulus to iron-carrying proteins might be lower in humans than in rats. ${ }^{32}$ Additional studies designed specifically for this purpose are, therefore, needed to determine the actual rate of iron filtration in humans.

\section{Renal tubular iron absorption and processing}

Once filtered by the glomerulus, iron is almost completely reabsorbed in the proximal tubules and distal tubules, where it is either stored in ferritin and utilized by the cells of the renal tubular epithelium, for example, incorporated into mitochondrial proteins, or exported via the basolateral membrane of tubular epithelial cells into the interstitium or circulation. The uptake and processing of iron in renal tubules depends on whether the metal ion is bound to protein, haem, or present as free ions, $\mathrm{Fe}^{2+}$ or $\mathrm{Fe}^{3+}$ (Figure 1). Iron released from haem is either stored in ferritin ${ }^{33}$ or exported from the cell.

\section{Transport of haem-bound iron}

Once filtered through the glomerulus, haemoglobin and myoglobin are reabsorbed by the epithelial cells in the proximal tubules via binding to megalin and cubilin, ${ }^{34}$ and haem is then released intracellularly. Haem is also taken up from the lumen of tubules via the haem importer, proton-coupled folate transporter (HCP1). ${ }^{35}$ The anti-inflammatory enzyme haem oxygenase 1 (HO1) then catalyses the partial degradation of intracellular haem, ${ }^{36}$ producing free iron and the tissueprotective anti-oxidants and vasodilators, biliverdin and CO. HO1 can also upregulate the expression of ferritin ${ }^{36}$ which is necessary for protection against AKI. ${ }^{37}$

\section{Receptor-mediated transport of nonhaem-iron}

Luminal protein-bound iron is endocytosed in proximal tubules by transferrin-specific pathways, such as the TFRC pathway, or by nonspecific receptors such as cubilin and megalin. In the distal tubule, iron bound to transferrin or NGAL is endocytosed via the NGALR. ${ }^{5,11,27,34,38,39}$ In the endosome, iron is released from the carrier protein after acidification, then reduced and exported to the cytosol via iron transporters, including DMT-1, and potentially by the zinc transporter ZIP14 (Zip14) or zinc transporter ZIP8 (Zip8), mucolipin-1 (MCOLN1) and mucolipin-2 (MCOLN2). ${ }^{11,18,40,41}$ To our knowledge it is not currently known how these transporters import iron into the cell. 
Table 1 | Proteins involved in iron metabolism in the kidney

\begin{tabular}{|c|c|c|c|c|}
\hline Protein & $\begin{array}{l}\text { Molecular } \\
\text { weight }(\mathrm{kDa})^{\star}\end{array}$ & Location $¥$ & Proposed function in the kidney & Reference(s) \\
\hline \multicolumn{5}{|l|}{ Iron acquisition } \\
\hline $\begin{array}{l}\text { Transferrin receptor } \\
\text { protein } 1\end{array}$ & $\sim 56$ & Proximal tubule: apical and basolateral & Uptake of transferrin & 11 \\
\hline Megalin & $\sim 600$ & Proximal tubule: apical & $\begin{array}{l}\text { Uptake of filtered NGAL, } \\
\text { haemoglobin, myoglobin and } \\
\text { lactoferrin for catabolism; } \\
\text { facilitates endocytosis of cubilin }\end{array}$ & 34 \\
\hline Cubilin & $\sim 460$ & Proximal tubule: apical & $\begin{array}{l}\text { Uptake of filtered transferrin, } \\
\text { haemoglobin and myoglobin for } \\
\text { catabolism }\end{array}$ & 34 \\
\hline NGALR & $\sim 58$ & $\begin{array}{l}\text { Medulla outer stripe, distal collecting duct and medullary } \\
\text { collecting duct: apical }\end{array}$ & Uptake of NGAL and transferrin & 39 \\
\hline Lactoferrin receptor & $\sim 34$ & Proximal tubule and distal tubule & Uptake of lactoferrin & 28,120 \\
\hline $\begin{array}{l}\text { Proton-coupled folate } \\
\text { transporter }\end{array}$ & $\sim 50$ & $\begin{array}{l}\text { Distal tubule and collecting duct and proximal tubule: } \\
\text { apical }\end{array}$ & Haem uptake & $35,42,121$ \\
\hline Haem oxygenase 1 & $\sim 33$ & $\begin{array}{l}\text { Proximal tubule, distal tubule and collecting duct: } \\
\text { intracellular; higher expression in distal tubule than in } \\
\text { proximal tubule }\end{array}$ & $\begin{array}{l}\text { Release of iron from haem and } \\
\text { production of bilirubin and } \mathrm{CO}\end{array}$ & $\begin{array}{l}18,36,38,55 \\
122\end{array}$ \\
\hline $\begin{array}{l}\text { Mucolipin } 1 \text { and } \\
\text { mucopilin } 2\end{array}$ & $\sim 65$ and $\sim 66$ & Unknown & $\begin{array}{l}\text { Efflux of } \mathrm{Fe}^{2+} \text { from endosomes } \\
\text { and lysosomes }\end{array}$ & 18,40 \\
\hline CD163 & $\sim 125$ & Expressed by interstitial macrophages & $\begin{array}{l}\text { Uptake of haem-haemopexin } \\
\text { complex; expression is } \\
\text { upregulated by haemoglobin }\end{array}$ & $16,17,66,108$ \\
\hline $\begin{array}{l}\text { Feline leukaemia virus } \\
\text { subgroup } C \text { receptor }\end{array}$ & 60 & $\begin{array}{l}\text { Probably basolateral; specific location in the nephron is } \\
\text { unknown }\end{array}$ & Basolateral export of haem & 38,47 \\
\hline \multicolumn{5}{|l|}{ Iron carriers } \\
\hline Transferrin ${ }^{\S}$ & 78 & Lumen & $\mathrm{Fe}^{3+}$ transfer & 11 \\
\hline Ferritin & 480 & $\begin{array}{l}\text { Proximal tubule: apical, basolateral or intracellular; } \\
\text { exported basolaterally }\end{array}$ & Storage of iron (as $\mathrm{Fe}^{3+}$ ) & $11,33,37,123$ \\
\hline NGAL & 24 & $\begin{array}{l}\text { Mesangial cells, proximal tubule, TAL, distal tubule, } \\
\text { medullary collecting duct and collecting ducts; secreted } \\
\text { by proximal and distal tubules }\end{array}$ & $\begin{array}{l}\text { Delivery of iron, role in AKI, } \\
\text { antimicrobial properties }\end{array}$ & $\begin{array}{l}19-21,39,55 \\
83,124\end{array}$ \\
\hline Haemoglobin $§$ & 68 & Mesangial cells & Haem carrier in erythrocytes & 34,125 \\
\hline Myoglobin $\$$ & 17 & Lumen & Haem carrier in myocytes & 34,126 \\
\hline Hepcidin & 2.8 & $\begin{array}{l}\text { Proximal tubule (S1 and S2): basolateral } \\
\text { TAL and medullary collecting duct: apical } \\
\text { Collecting tubule and cortical collecting duct: cytosolic } \\
\text { Distal tubule and collecting ducts }\end{array}$ & $\begin{array}{l}\text { Regulation of basolateral } \\
\text { ferroportin expression, binds } \mathrm{Fe}^{2+} \text {, } \\
\text { has antibacterial properties and } \\
\text { protects against AKI }\end{array}$ & $5,6,9,127$ \\
\hline Lactoferrin & 80 & Distal tubule and collecting ducts & Binds $\mathrm{Fe}^{2+}$ and is antibacterial & $27-29,34,120$ \\
\hline Haemopexin§ & 60 & Mesangium and cortex & Binds haem & $\begin{array}{l}38,47,62,93 \\
128\end{array}$ \\
\hline Haptoglobin" & 88 & Cortex, including the proximal tubule & $\begin{array}{l}\text { Binds haemoglobin and cannot } \\
\text { be filtered }\end{array}$ & 49 \\
\hline
\end{tabular}

*Approximate molecular weights based on the entries for human protein in the online Universal Protein Resource database. ₹Suggested localization does not exclude expression elsewhere in

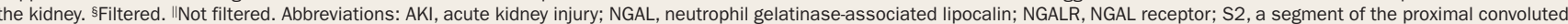
tubule; S3, the straight segment of the proximal tubule; TAL, thick ascending limb of the loop of Henle. 


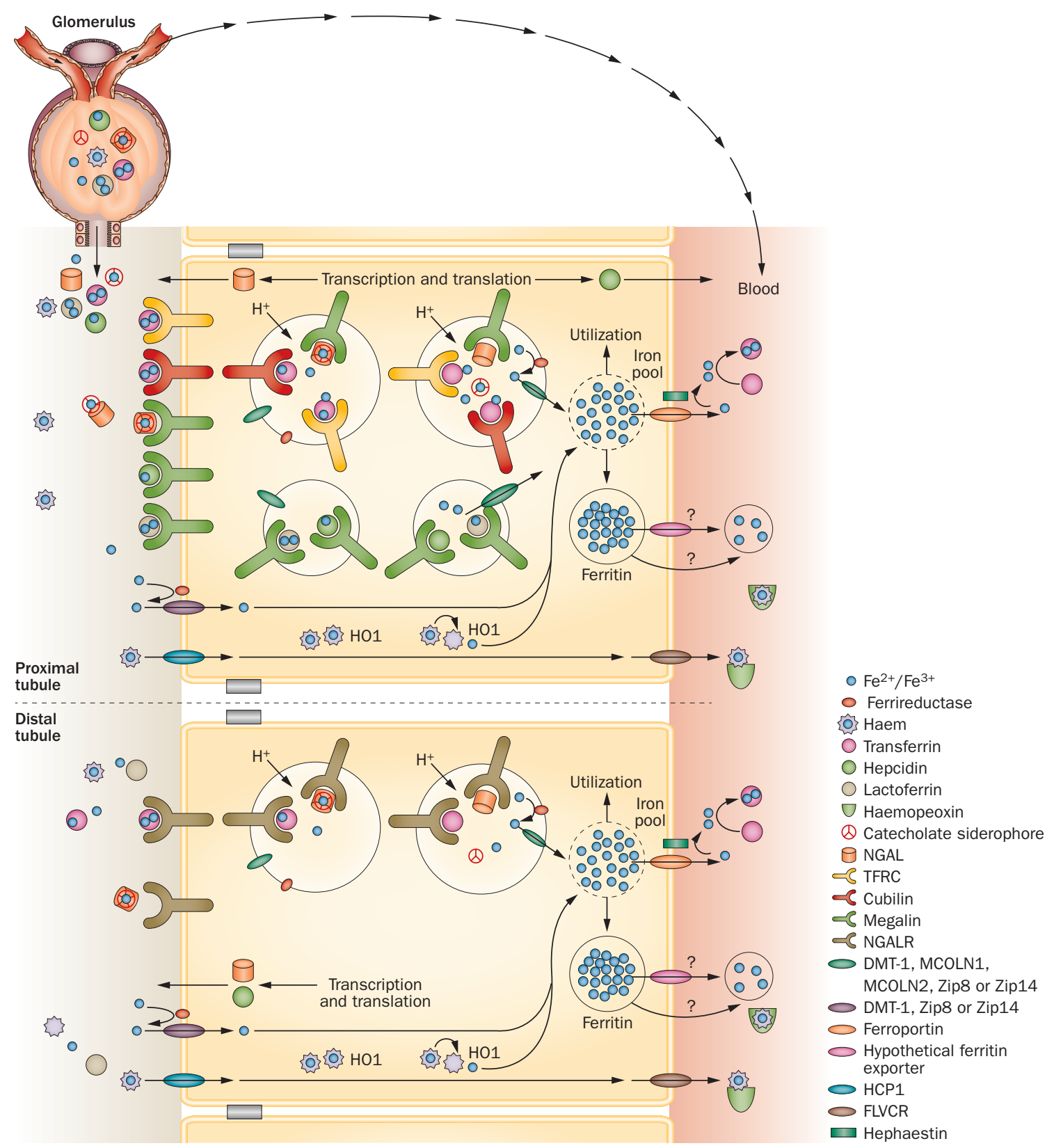

Figure 1 Kidney iron transport. Circulating iron enters the renal tubular lumen after glomerular filtration. ${ }^{11,26}$ Iron bound to transferrin, NGAL and other proteins and peptides, including lactoferrin and hepcidin, is reabsorbed in the proximal tubule after binding to the transferrin-specific TFRC or the nonspecific receptors cubilin and megalin, respectively. Transferrinbound and NGAL-bound iron is also reabsorbed in the distal tubule via NGALR. 5,11,20,27-29,34,39 Free iron is reabsorbed via the transporters DMT-1, Zip8 and Zip14, and haem is reabsorbed via HCP1. ${ }^{35,38,42}$ Intracellular free iron may be stored in ferritin, utilized, for instance incorporated into functional proteins, or exported basolaterally via ferroportin. ${ }^{11,44}$ Intratubular iron can also be exported bound to ferritin. ${ }^{33}$ Hepcidin and NGAL can be secreted from the apical surfaces of renal tubular cells, where these proteins can bind to and possibly detoxify iron. Abbreviations: DMT-1, divalent metal transporter 1; FLVCR, feline leukaemia virus subgroup C receptor; HCP1, proton-coupled folate transporter; H01, haem oxygenase 1; MCOLN1, mucopilin 1; MCOLN2, mucopilin 2; NGAL, neutrophil gelatinase-associated lipocalin; NGALR, NGAL receptor; TFRC, transferrin receptor protein 1; Zip8, zinc transporter ZIP8; Zip14, zinc transporter ZIP14.

Transporter-mediated uptake of free iron

Filtered free iron, and iron released from proteins as a result of acidification of the filtrate as it passes along the nephron, enters the tubular epithelial cells after reduction by cytochrome $b$ reductase 1 (DCYTB), via the apical ion transporters DMT-1 (in both proximal and distal tubules), Zip8 and Zip14 (currently only identified in proximal tubules)..$^{6,11,18,41-43}$ Interestingly, some evidence suggests that increased iron uptake via Zip8 and Zip14 could be responsible for the lack of increased urinary iron excretion in DMT-1-deficient rodents. ${ }^{18}$ 
Iron export from tubular epithelial cells

Iron can be exported into the interstitial fluid and circulation through the basolateral membrane of renal tubular epithelial cells by ferroportin ${ }^{11,44}$ or exported bound to haem via the haem exporter feline leukaemia virus subgroup C receptor (FLVCR). ${ }^{2,39}$ FLVCR is essential to haem export, as shown in FLVCR-knockout mice, which spontaneously accumulate iron in the kidney, ${ }^{45}$ and also requires the extracellular presence of a suitable haembinding protein (albumin or preferably haemopexin), to enable substantial haem export. ${ }^{38,45}$ Macrophages can produce haemopexin ${ }^{46}$ and express the haemopexin receptor low-density lipoprotein receptor-related protein 1 (LRP-1). ${ }^{47,48}$ On the basis of these observations, we speculate that export of haem and its subsequent degradation might be facilitated by interstitial macrophages through production of haemopexin, as well as binding of haeme-carrying haemopexin to LRP-1.

Interstitial macrophages also express the haemoglobinhaptoglobin complex receptor, CD163. ${ }^{16}$ Although no firm evidence yet exists, interstitial macrophages could conceivably also produce the haemoglobin-binding protein, haptoglobin (which binds to, takes up and degrades haemoglobin). ${ }^{49,50}$ In fact, elevated haptoglobin production has been detected in the renal cortex in several animal models of AKI, which could be interpreted as AKI-associated haptoglobin production by interstitial macrophages. ${ }^{49}$ Furthermore, in patients with AKI, an increase in urinary haptoglobin:creatinine ratio was observed, which almost exactly paralleled NGAL excretion in these patients haptoglobin occurs in these patients. This observation suggests that a kidneyinjury-induced increase in haptoglobin occurs in these patients. ${ }^{49}$ Interestingly, in vitro and ex vivo studies indicate that uptake of the haptoglobin-haemoglobin complex by macrophages may protect against ironinduced tissue injury by upregulation of CD163 expression, secretion of the anti-inflammatory cytokine IL-10 and upregulation of $\mathrm{HO} 1$ expression..$^{50}$

\section{Intracellular iron trafficking}

The nature of intracellular iron trafficking in renal tubular epithelial cells is unclear. Conventionally, iron was thought to enter the cytosol via export from endosomes, release from degraded haem or import via apical ion transporters, and was then thought to be utilized, stored in ferritin or exported into the interstitial fluid and circulation. However, this simplified view of intracellular iron trafficking might not explain all reported observations. Firstly, the manner in which iron is taken up seems to be a determinant for its mode of intracellular trafficking and metabolism. For example, micromolar concentrations of ferric citrate but not ferrous citrate injure kidney cells in vitro, and this deleterious effect of ferric citrate is enhanced by the presence of transferrin. ${ }^{51}$ By contrast, engulfment and degradation of intact red blood cells (which contain substantial amounts of iron) by renal tubular epithelial cells does not seem to be toxic to the epithelial cells in vitro. ${ }^{17,52}$ Furthermore, studies in human erythroleukaemia cells showed that only some iron chelators seem to affect mitochondrial iron uptake, and that the various forms of cytosolic iron contribute differentially to mitochondrial iron delivery in vitro. ${ }^{53}$ Finally, studies in yeast and mammalian cells suggest that mitochondrial and cytosolic iron transport pathways utilize separate delivery routes and corresponding chaperone proteins. ${ }^{54}$

\section{Regulation of renal iron transport}

The regulation of renal iron transport might serve several possible purposes. One might be to protect the kidney against effects of iron toxicity. Intracellular iron content controls the expression of ferritin and TFRC, ${ }^{26}$ and probably also the expression of ferroportin and DMT- $1,{ }^{2}$ in the kidney via the IRE-IRP post-transcriptional regulatory system. Furthermore, an iron-enriched diet or parenteral administration of iron to mice increased the expression of $\mathrm{HO} 1,{ }^{55} \mathrm{NGAL}^{55}$ and ferritin, ${ }^{56}$ and decreased the expression of TFRC ${ }^{56}$ in the kidney, as well as increasing urinary iron excretion. ${ }^{11}$ Another function might be the prevention of urinary iron loss, either to conserve the availability of this scarce ion or to protect against urinary tract infections. ${ }^{20}$ This suggestion is supported by the fact that the kidney harbours an array of apical ion receptors and transporters that mediate cellular iron uptake, including megalin, cubilin, NGALR, DMT-1, Zip8 and Zip14 (Table 1). In addition, an iron-deficient diet or haemolytic anaemia increased the mRNA and/or protein expression of DMT-1 in the kidneys of mice and rats ${ }^{6,11,56}$ and ferroportin expression in the kidneys of mice. ${ }^{6}$ These data suggest that regulation of renal iron transport is biased toward the minimization of urinary iron loss, to ensure adequate iron bioavailability for erythropoesis, regardless of the systemic iron content.

\section{Iron-induced kidney injury}

Inflammation and/or oxidative stress can upregulate the expression of DMT- $1,{ }^{18}$ Zip8, Zip14, ${ }^{41}$ lactoferrin, ${ }^{28}$ hepci$\operatorname{din}^{5}$ and NGAL, ${ }^{57-59}$ possibly enabling increased uptake of iron in the renal tubules. Under physiological conditions, minor (or initial) inflammation or stress might modulate the expression of these proteins to enable increased sequestration of iron into kidney cells or to minimize extracellular iron-induced injury. However, under pathological conditions, in which extensive inflammation and/ or oxidative stress may occur, these and other mechanisms might cause excessive iron retention in the kidney tubules and consequent iron-induced kidney injury.

The kidney can be exposed to toxic levels of bound iron (for example, in transferrin), and free iron, as a result of systemic iron overload (which may be diet or disease-related), increased delivery of iron into the kidney tubules, or alterations in cellular iron localization or compartmentalization in the kidney. A role for iron in kidney injury is suggested by evidence that iron and ironcontaining molecules can cause direct injury to renal tubular cells in vitro ${ }^{36,51,52,60,61}$ and in vivo..$^{36,62}$ In addition, kidney and urinary iron content is increased

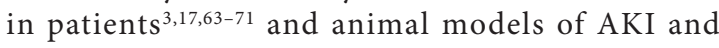
CKD. ${ }^{3,6,14,71-80}$ Finally, the severity of kidney injury can be reduced by iron-deficient diets, the use of iron 


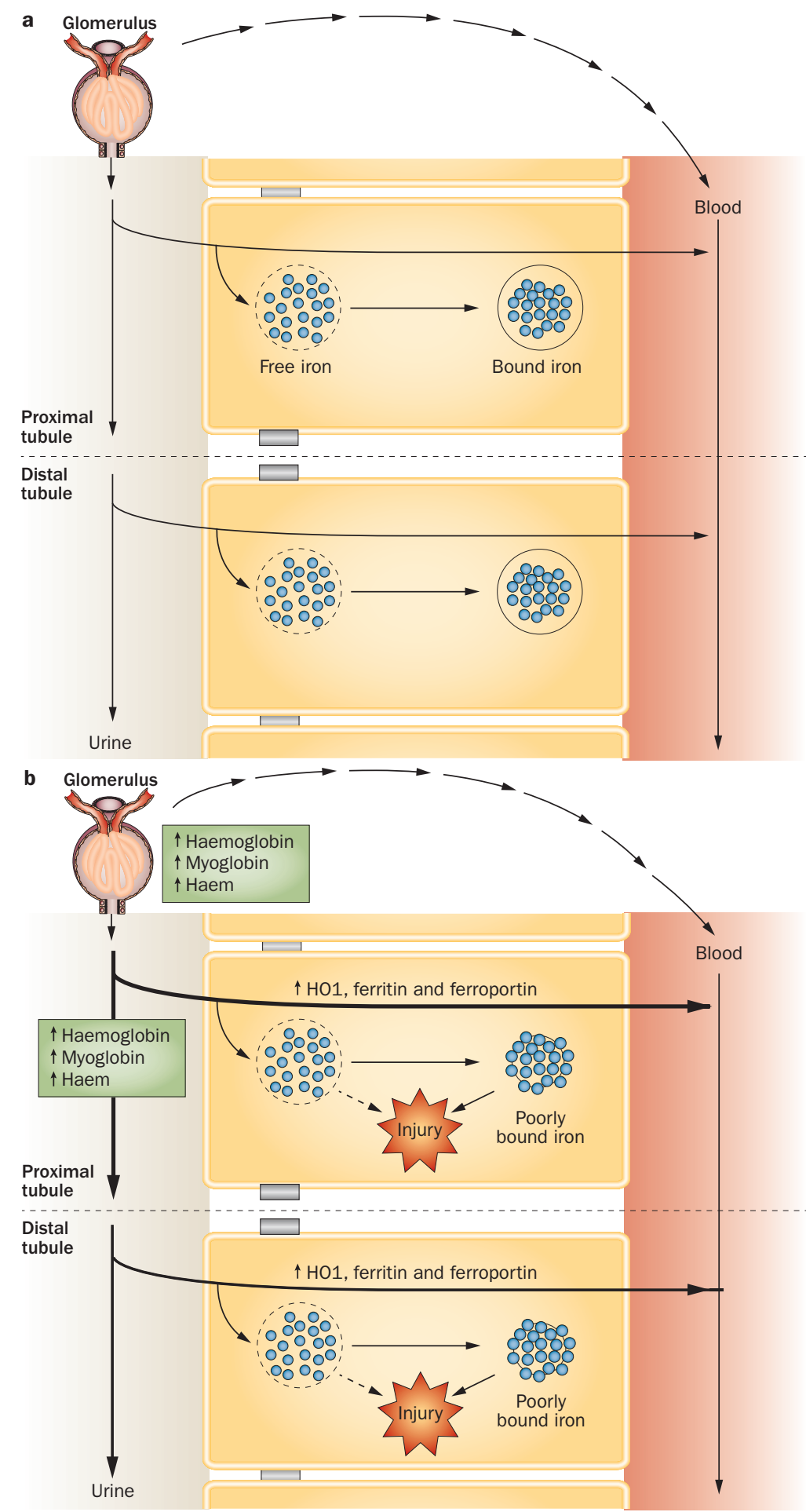

chelators or treatment directed at reducing iron-related oxidative stress in animal models. ${ }^{3,15,19,71,79,81-83}$ Direct evidence of renal toxic effects of iron is, however, limited in humans. ${ }^{3,24,25,63,84-87}$ On the basis of current evidence, we propose four pathways for iron-induced kidney injury (Figures 2-5).

\section{Haem-related diseases}

Severe haemolysis and rhabdomyolysis can result in iron-induced kidney injury by causing a massive
4 Figure 2 | Iron filtration under physiological or disease conditions. a | A limited quantity of iron in serum is filtered through the glomerulus. This iron is predominantly reabsorbed by the epithelial cells in the proximal tubules via receptors or metal ion importers. Absorbed iron is stored in ferritin, incorporated into functional proteins or exported as haem or $\mathrm{Fe}^{2+}$. b | Iron metabolism in haemolysis and rhabdomyolysis. The massive increase in circulating haem results in its excessive filtration. ${ }^{64,68,72,90,91}$ Despite the upregulation of $\mathrm{HO1}$, ferritin, ferroportin, haemopexin, haptoglobin and CD163 expression in the kidney, more iron is reabsorbed by renal tubular epithelial cells than is exported and stored in ferritin, resulting in iron accumulation in the renal epithelium, tubular damage and cell death. ${ }^{1,3,17,36,62,65-67,72,74,88-92}$ Interstitial macrophages may be overwhelmed by excess iron released into the interstitium, resulting in interstitial iron accumulation and damage. The thickness of the arrows indicates the relative amounts of iron exposure. Abbreviation: HO1, haem oxygenase 1.

increase in circulating levels of haemoglobin, myoglobin and haem ${ }^{47}$ (Figure $2 \mathrm{~b}$ ). This increase overwhelms the capacity of circulating haemopexin and haptoglobin to bind haem, haemoglobin and myoglobin, as shown by decreased concentrations of circulating haemopexin and haptoglobin. ${ }^{47,66}$ Consequently, glomerular filtration of haem increases, and the increased concentration of haem in the renal tubules lumen upregulates reabsorption of haem until the reabsorptive capacity of the tubules becomes saturated.

Several lines of evidence support this mechanism. Urinary iron levels are elevated in patients with haemolytic diseases or red cell aplasia ${ }^{64,68}$ and in animal models of haem-induced injury. ${ }^{72}$ Decreased intracellular expression of prohepcidin (the prohormone form of hepcidin) in the proximal tubule basal membrane $e^{6}$ and increased expression of DMT-1 and ferroportin in the proximal tubule have been detected in an animal model of haemolytic anaemia. ${ }^{6}$ In addition, iron reabsorption in the tubules is increased beyond the capacity of the epithelial cells to safely store iron in ferritin or to export it via the basolateral membrane. Despite the elevated renal expression of HO1, ferritin, ferroportin, haptoglobin, CD163, and haemopexin (the latter presumably in interstitial macrophages) ${ }^{46,62}$ that occurs in both patients ${ }^{66,67,88}$ and animal models of haem-related disease, ${ }^{6,49,62,88}$ tissue damage occurs (Table 2 and Supplementary Table 1 online).

Under conditions of iron excess, interstitial macrophages in the kidney probably modulate the expression of iron-related and anti-inflammatory proteins, including haemopexin, haptoglobin, CD163 and IL-10 to stimulate iron export out of the renal tubular epithelial cells and thereby minimize epithelial damage, and to detoxify interstitial iron by means of storage in ferritin or export into the circulation. However, in patients with severe or persistent haemolytic or rhabdomyolytic disease, which causes massive iron delivery to the kidney, interstitial macrophages might not be able to effectively store or export iron at the same rate as it is delivered and taken up by iron importers and receptors that mediate iron uptake, thereby leading to further 
Figure 3 | The effects of systemic iron overload. a | In patients with hereditary haemochromatosis, increased transferrin saturation and increased non-transferrin-bound iron levels in serum result in increased iron filtration. ${ }^{12,13}$ In the forms of hereditary haemochromatosis caused by hepcidin and haemojuvelin gene mutations, the rate of iron export from renal tubular cells is lower than that of iron absorption, despite upregulated expression of ferritin and ferroportin, resulting in iron accumulation and tissue damage in the kidney. ${ }^{73}$ In a mouse model of Hfe-related hereditary haemochromatosis, the mRNA expression of ferroportin, hephaestin, cytochrome $b$ reductase 1 and divalent metal transporter 1 is decreased, possibly limiting transepithelial iron transport, but not sufficiently to prevent iron accumulation in the kidney. ${ }^{73,75,94,95} \mathbf{b}$ | Dietary or transfusion-related systemic iron overload (in patients with no or minimal haemolysis) can cause increased iron filtration and increased iron uptake in renal tubular cells. The expression of $\mathrm{H01},{ }^{55} \mathrm{NGAL}^{55}$ and ferritin ${ }^{56}$ is increased and the expression of TFRC is decreased; ${ }^{56}$ however, these modulations could still result in excessive iron uptake, insufficient protection against the toxic effects of iron and consequent tubular damage. The thickness of the arrows indicates the relative amounts of iron exposure. Abbreviations: H01, haem oxygenase 1; NGAL, neutrophil gelatinase-associated lipocalin; TFRC, transferrin receptor protein 1.

interstitial and tissue damage. Indeed, iron-induced damage to the tubules and/or interstitia is implicated by reports of haemosiderin deposits in the proximal tubule and distal tubule, haem-cast formation, tubular necrosis, cortical atrophy, interstitial fibrosis and distal tubule DNA damage in patients with haemolysis and rhabdomyolysis ${ }^{1,17,65-67,74,89-92}$ as well as in animal models of myohaemoglobin-induced AKI. 3,36,62,72,74,88,89,92

A link between haem or haem-containing proteins, for example haemoglobin and myoglobin, and AKI has been established. ${ }^{93}$ In this study, AKI induced an increase in circulating free haem, regardless of the aetiology of AKI. In addition, AKI increased the expression of haemopexin in the liver. Haemopexin was secreted into the circulation, filtered and reabsorbed by the kidney. ${ }^{93}$ Furthermore, exogenous haemopexin attenuated free-iron-mediated cell death in a human kidney proximal tubule cell line (HK-2), and lipopolysaccharide, but not iron, induced haemopexin expression in HK-2 cells in vitro. ${ }^{93}$ The researchers suggested that the increase in circulating haemopexin results in removal of circulating free haeme, which probably has cytoprotective effects in the kidney. ${ }^{93}$ These results suggest that proper handling of haem probably has an important role in attenuating AKI in general. These results also suggest that iron metabolism in the kidney is the result of a multiorgan effort against the potential toxic effects of this metal.

\section{Systemic iron overload}

Systemic iron overload can be hereditary, for example in $H F E$-related hereditary haemochromatosis, or acquired, for example by an excessive number of blood transfusions. An overload of iron is associated with increased

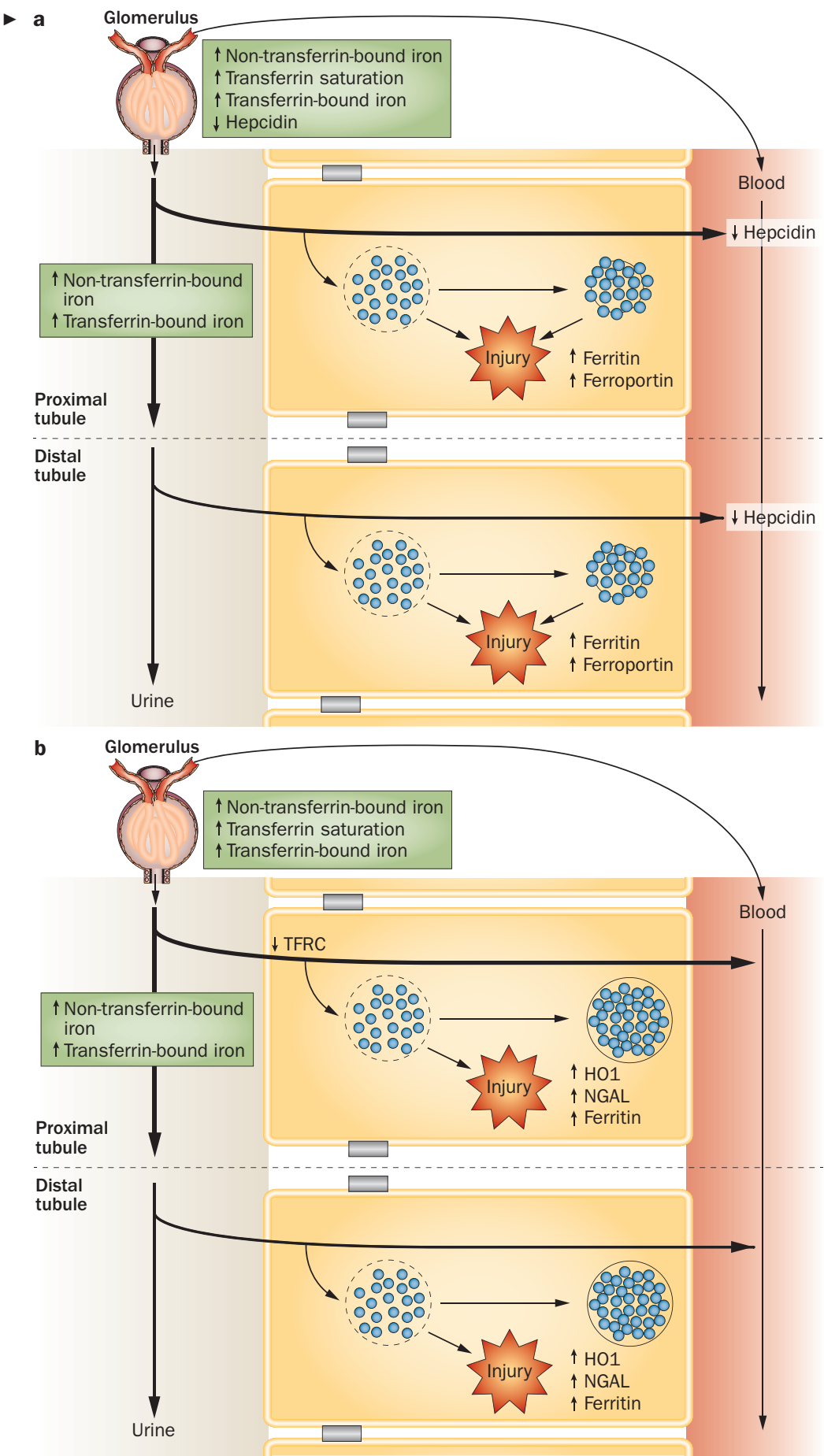

iron saturation of transferrin ${ }^{12,13}$ and an increase in the amount of circulating nontransferrin-bound iron. ${ }^{12,13}$ This iron might be filtered, ${ }^{20}$ and could cause iron overload in the kidney, as shown in patients and animal models of systemic iron overload (Table 1 and Supplementary Table 2 online). ${ }^{63,65,68,69,73,75,94}$ Filtered iron can cause renal tubular epithelial cell damage due to iron uptake that exceeds the cells' capacity for iron storage in ferritin and iron export (Figure 3).

Currently, the mechanisms through which systemic iron overload induces kidney injury are unclear. For 


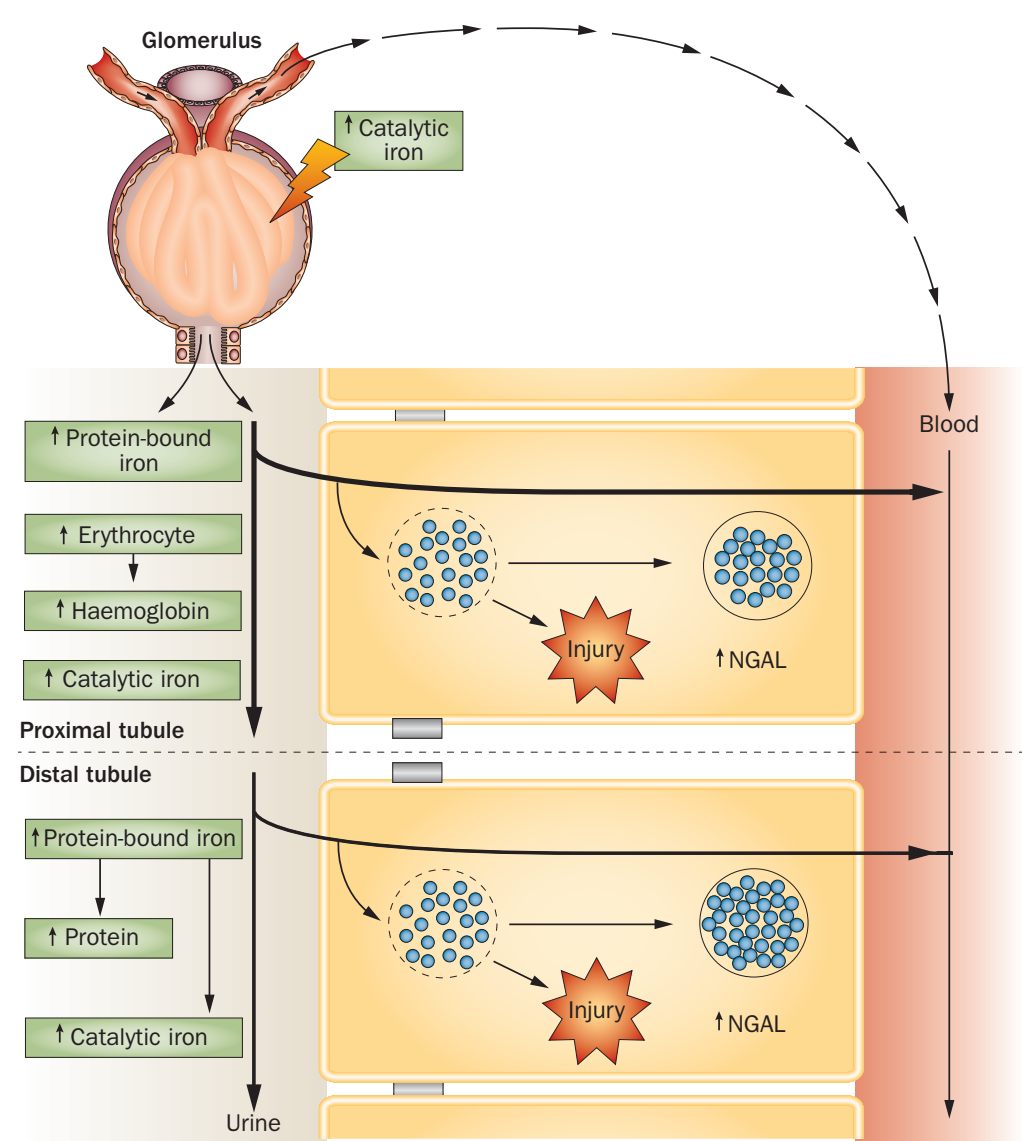

Figure 4 | Iron metabolism in glomerulopathy. In glomerular disease, the glomerular barrier is damaged, resulting in leakage of catalytic iron from glomerular cells, increased filtration of protein-bound iron, and leakage of red blood cells through the glomerulus. Red blood cells can subsequently lyse in the tubular lumen, resulting in the substantial release and luminal presentation of haemoglobin to the renal tubular cells. These effects can result in increased iron absorption in the renal tubules, tubulointerstitial iron accumulation and tissue damage, accompanied by increased levels of NGAL in renal tubular cells. ${ }^{3,14,16,17,22,52,70,71,77,80}$ The thickness of the arrows indicates the relative amounts of iron exposure. Abbreviation: NGAL, neutrophil gelatinase-associated lipocalin.

example, HFE-knockout $\left(\mathrm{Hfe}^{-/-}\right)$mice show decreased mRNA expression of the ferritin light chain (a subunit of ferritin), hephaestin and DCYTB. When fed an ironenriched diet, these mice showed lower expression of DMT-1 and ferroportin than did wild-type mice. ${ }^{56}$ These differences might indicate compensatory mechanisms that attempt to minimize transepithelial iron transport and improve the effectiveness of iron storage in renal tubular epithelial cells in a safe manner, possibly by increasing the proportion of the ferritin heavy chain in the ferritin protein, which might increase the amount of iron that can be bound by this protein. ${ }^{33}$ This hypothesis is supported by observations of parallel upregulation of ferroportin and DMT-1 in anaemic mice, ${ }^{6}$ probably to minimize iron losses during states of increased demand for use in erythropoiesis. Notably, Hfe gene knockout resulted in iron accumulation in the kidney in some, ${ }^{75,94}$ but not all animal studies. ${ }^{73,95}$

The mechanisms proposed here do not fully explain the renal complications of HFE-related hereditary haemochromatosis. To complicate matters further, in two other models of hereditary haemochromatosis (hepcidinknockout and haemojuvelin-knockout mice) expression of ferroportin in the kidney increased ${ }^{73}$ (in contrast to the decreased expression of ferroportin observed in mice with HFE-related hereditary haemochromatosis). ${ }^{73}$ Nevertheless, these mice accumulate iron in the kidney and exhibit increased urinary iron excretion. ${ }^{73}$ Of note, all three genetic abnormalities (HFE-knockout, hepcidinknockout and haemojuvelin-knockout) result in decreased systemic hepcidin levels. We can only speculate that in the latter two models, for currently unknown reasons, the rate of apical iron uptake exceeds the rate of basolateral iron export. Unfortunately, data on iron content in the kidney in patients with hereditary haemochromatosis are limited to a single case report, published in $1918 .{ }^{69}$

Iron overload in the kidney was also reported in mice fed an iron-enriched diet ${ }^{56}$ and in patients with transfusion-related iron overload $\mathrm{d}^{63,65,68}$ in whom the increased iron load was associated with renal tubule dysfunction. ${ }^{63,84,86,87}$ These findings demonstrate a link between iron accumulation and renal tubular damage. We speculate that the processes leading to iron overload and injury in the kidney after blood transfusion might be more easily explained than those underlying hereditary haemochromatosis. Firstly, blood transfusions often cause mild haemolysis, which may contribute to iron loading and injury in the proximal tubules, as discussed previously. ${ }^{65,91,96}$ Secondly, patients with sickle cell disease and $\beta$-thalassaemia, who need repeated blood transfusions, ${ }^{5,97-100}$ often have chronic inflammation, which may be accompanied by increased oxidative stress. ${ }^{97-100}$ Inflammation and oxidative stress probably induce the expression of hepcidin in both the liver and kidney, increasing both serum and local levels of this hormone, ${ }^{5}$ and thereby causing iron trapping along the entire nephron. ${ }^{44}$

\section{Glomerulopathies}

Proteinuria and haematuria ${ }^{16}$ are common manifestations of glomerular disease, and the best predictors for progression of CKD. ${ }^{16,101}$ These symptoms have been linked with iron accumulation in the kidney, ${ }^{3,14,17,70,71,77}$ renal tubular cell damage ${ }^{3,11,17}$ and elevated urinary iron levels ${ }^{102-105}$ in both patients with glomerulopathies ${ }^{3,17,70}$ and animal models of glomerular disease (Table 2 and Supplementary Table 3 online). ${ }^{14,17,71,77}$ Interestingly, lysosomal iron accumulation in the proximal tubule was the only independent predictor of both functional and structural damage to the proximal tubule in rats with proteinuria induced by puromycin (an inhibitor of serine peptidase and metallopeptidase). ${ }^{77}$ This finding suggests that iron is an important contributor to AKI under conditions of proteinuria. In addition, administration of iron chelators ameliorated proteinuria and endstage renal disease (ESRD) in animal models of CKD and minimal change nephrotic syndrome. ${ }^{3,71}$ Furthermore, an iron-deficient diet prevented progression of kidney dysfunction and was associated with a trend toward reduced hypertension in mouse models of glomerular disease. ${ }^{3,81}$ Importantly, a study in a rat model of CKD 
showed that dietary iron restriction significantly suppressed the development of hypertension, confirming previous results in mice. ${ }^{81,106}$ Clinical data are limited, although urinary levels of catalytic iron are elevated in patients with diabetic nephropathy before the onset of microalbuminuria, ${ }^{3}$ which argues for a possible role of excessive tubular iron delivery in the pathogenesis of diabetic nephropathy and in the development of CKD, as diabetes is the major cause of CKD in developed countries. ${ }^{107}$ In addition, preliminary findings suggest that the use of iron chelators improved renal function in patients with glomerular disease. ${ }^{24}$

Sources of iron that are likely to be involved in glomerulopathy-associated renal tubular cell damage include catalytic iron originating from damaged glomerular cells, ${ }^{3}$ transferrin-bound iron originating from serum $^{51}$ and haemoglobin derived from intratubular lysis of erythrocytes. ${ }^{16,17,52}$ Surprisingly, however, haemoglobin derived from (apical) phagocytosis and intracellular degradation of erythrocytes is not likely to be involved in glomerulopathy-associated renal tubular cell damage, as phagocytosis and degradation of erythrocytes in proximal tubular epithelial cells (thereby potentially releasing substantial amounts of intracellular haemoglobin) is not cytotoxic in vitro. ${ }^{17,52}$ Results from animal and human studies suggest that in the initial stages of proteinuric glomerular disease, excessive luminal iron levels predominantly affect the proximal tubule. ${ }^{3}$ As the disease progresses, the continued excess of iron may overwhelm the iron-handling mechanisms of the distal tubule, resulting in haemosiderin deposits in proximal and distal tubule cells, as shown in a mouse model of nephrotic syndrome..$^{14}$ In patients with haematuric glomerular disease, excessive luminal haemoglobin could cause tubular damage similar to that observed in patients with intravascular-haemolysis-induced kidney injury (Figure 4). This hypothesis is supported by the results of a study showing that CD163 expression, $\mathrm{HO} 1$ expression and oxidative stress correlated positively with renal tubular erythrocyte casts and necrosis in patients with AKI. ${ }^{108}$ Moreover, CD163-expressing macrophages surrounding the renal tubules were filled with erythrocytes and loaded with haemosiderin deposits. ${ }^{108}$

Interestingly, expression of NGAL is increased in the kidney in animal models of both nephrotoxic serum nephritis (although the location in the nephron where this increased expression occurs has not been determined) and CKD (in which expression is increased in the proximal and distal tubules). A decrease in NGAL expression (for example in NGAL-knockout mice) resulted in attenuation of glomerular and tubulointerstitial damage in the kidney and proteinuria, as well as slow progression of kidney failure. ${ }^{19,21,22,80}$ This finding might be related to the proinflammatory properties of NGAL, but excessive local or intracellular NGALmediated iron mobilization cannot be excluded. By contrast, in another study, NGAL-knockout mice exhibited more pronounced glomerular damage and increased proteinuria, which was attributed to a lack of inhibition of inflammation by NGAL. ${ }^{109}$

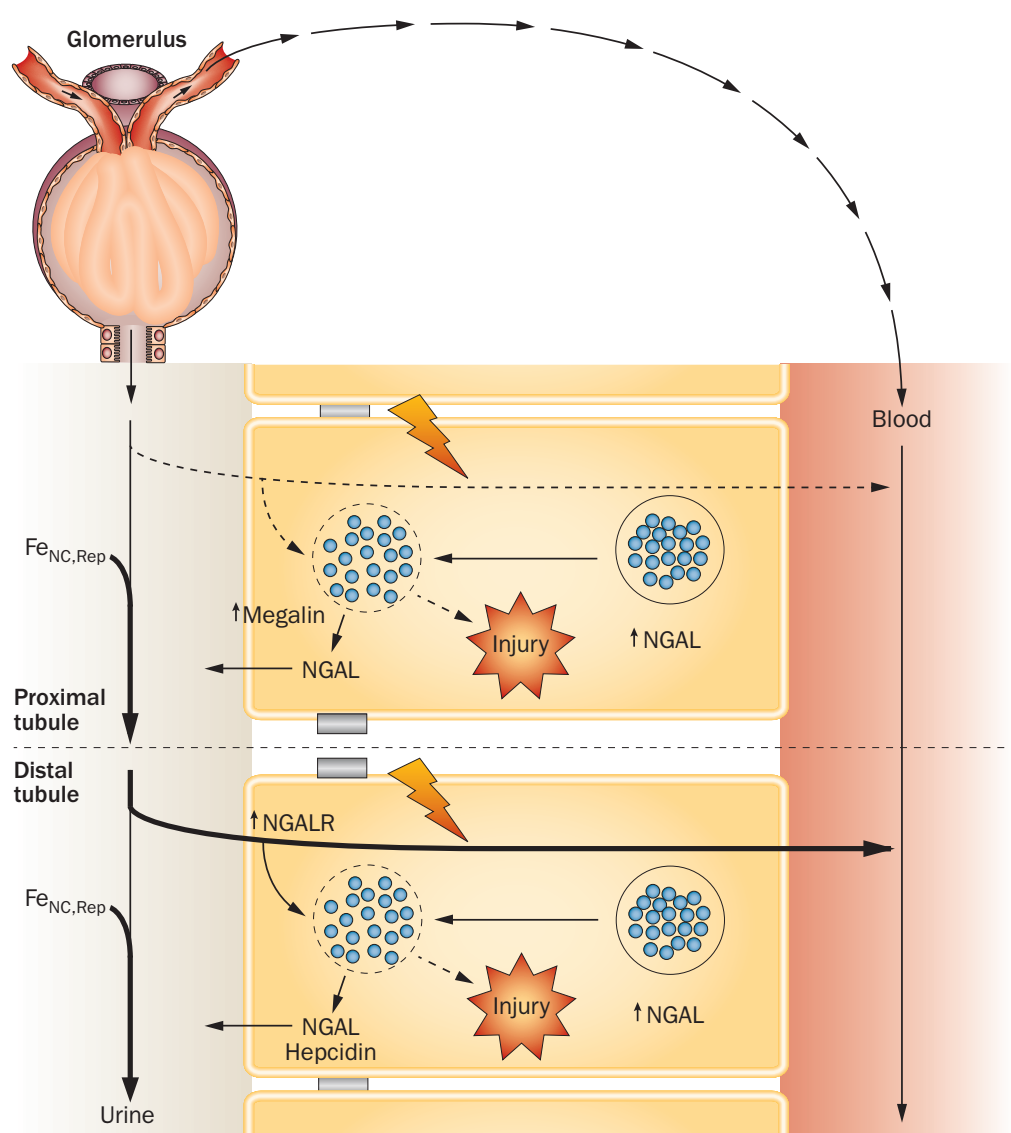

Figure 5 | Iron metabolism in ischaemia-reperfusion injury. During ischaemia, tubular epithelial cells are deprived of nutrients, which causes necrosis and release of catalytic iron into the tubule lumen, exposing neighbouring cells to iron damage. Reperfusion brings additional iron and carries the released catalytic iron further down the nephron, causing propagation of iron-induced kidney damage. ${ }^{15,19,61,82,110}$ NGAL expression is increased in the proximal and distal tubules and NGAL is subsequently secreted. ${ }^{19}$ Hepcidin expression in the tubules is probably also increased in ischaemia-reperfusion injury. This hepcidin is secreted from the apical surface of epithelial cells $s^{8-10}$ and, together with NGAL, could aid in protection of the kidney against iron-induced injury. Abbreviations: $\mathrm{Fe}_{\mathrm{NC}, \mathrm{Rep}}$, iron released from necrotic cells or delivered during reperfusion; NGAL, neutrophil gelatinase-associated lipocalin; NGALR, NGAL receptor.

\section{Ischaemia-reperfusion injury to the kidney}

Ischaemia and reperfusion cause kidney injury through iron-mediated mechanisms. ${ }^{15,19,61,82}$ During ischaemia, a decrease in $\mathrm{pH}$ or superoxide-induced reduction of $\mathrm{Fe}^{3+}$ causes dissociation of protein-bound intracellular iron, thereby increasing the levels of catalytic iron. The increase in catalytic iron could contribute to oxidative stress and cellular damage, resulting in tubular necrosis. ${ }^{15,19,61,82,110}$ Furthermore, reperfusion (which both brings in additional iron to the kidney and carries the iron released from necrotic kidney cells further down the nephron), exacerbates the tissue damage (Figure 5). ${ }^{15,61}$ The important role of iron in ischaemia-reperfusion injury is underlined by studies showing that infusion of the iron-chelating agents deferoxamine and apotransferrin improved kidney function after induction of kidney ischaemia-reperfusion injury in rats and mice, respectively. ${ }^{15,82}$ In addition, pretreatment of cultured proximal tubular epithelial cells with either deferoxamine 


\begin{tabular}{|c|c|c|c|c|c|}
\hline Disease & $\begin{array}{l}\text { Iron level } \\
\text { in kidney }\end{array}$ & $\begin{array}{l}\text { Urinary iron } \\
\text { excretion }\end{array}$ & $\begin{array}{l}\text { Iron-associated } \\
\text { kidney injury }\end{array}$ & $\begin{array}{l}\text { Effective intervention for iron-induced } \\
\text { kidney injury }\end{array}$ & Reference(s) \\
\hline \multicolumn{6}{|l|}{ Animal studies } \\
\hline $\begin{array}{l}\text { Haem-related } \\
\text { disease }\end{array}$ & $\uparrow$ & $\uparrow$ & Yes & $\begin{array}{l}\text { Deferoxamine infusion attenuated kidney } \\
\text { dysfunction and oxidative stress }\end{array}$ & $1,36,62,72,74,89$ \\
\hline $\begin{array}{l}\text { Systemic iron } \\
\text { overload }\end{array}$ & $\uparrow$ & $\uparrow$ & Yes & $\begin{array}{l}\text { Iron-deficient diet decreased nonhaem iron } \\
\text { and bleomycin-detectable iron in the } \\
\text { kidney }\end{array}$ & $\begin{array}{l}11,73,75,94,95 \\
129\end{array}$ \\
\hline Glomerulopathy & $\uparrow$ & $\uparrow$ & Yes & $\begin{array}{l}\text { Iron-deficient diet prevented an increase in } \\
\text { urinary iron excretion and in tubular } \\
\text { nonhaem iron content in a mouse model } \\
\text { of passive Heymann nephritis }\end{array}$ & $\begin{array}{l}3,14,71,77,81 \\
106\end{array}$ \\
\hline $\begin{array}{l}\text { Ischaemia- } \\
\text { reperfusion injury }\end{array}$ & $\uparrow$ & $\uparrow$ & Yes & $\begin{array}{l}\text { Administration of deferoxamine decreased, } \\
\text { and infusion of iron increased damage and } \\
\text { oxidative stress in a model of ischaemia- } \\
\text { reperfusion injury to the kidney }\end{array}$ & $\begin{array}{l}15,19,61,82,83 \\
110\end{array}$ \\
\hline \multicolumn{6}{|l|}{ Human studies } \\
\hline $\begin{array}{l}\text { Haem-related } \\
\text { disease }\end{array}$ & $\uparrow$ & $\uparrow$ & Yes & Urine alkalinization not effective & $1,17,53,64-68$ \\
\hline $\begin{array}{l}\text { Systemic iron } \\
\text { overload }\end{array}$ & $\uparrow$ & $\uparrow$ & Yes & Iron chelators (in thalassaemia) & $\begin{array}{l}63,65,68,69,84 \\
86,87,94,95\end{array}$ \\
\hline Glomerulopathy & $\uparrow$ & $\uparrow$ & Yes & Iron chelators and urine alkalinization & $\begin{array}{l}3,17,24,25,70 \\
102-105,108\end{array}$ \\
\hline $\begin{array}{l}\text { Ischaemia- } \\
\text { reperfusion injury }\end{array}$ & NA & NA & Indirect & NA & 9 \\
\hline
\end{tabular}

or hydroxyethyl starch-conjugated deferoxamine conferred protection against ischaemia-induced lethal cell injury. ${ }^{15,61,82}$ Administration of NGAL also attenuated kidney injury in animal models of ischaemiareperfusion injury (Table 2 and Supplementary Table 4 online). ${ }^{19,83,111}$ By contrast, infusion of iron-saturated transferrin, which thus cannot bind more iron, did not improve kidney function in a mouse model of ischaemiareperfusion kidney injury. ${ }^{82}$ The beneficial effect of iron-chelating agents and NGAL against ischaemiareperfusion injury to the kidney may be a result of binding (and, thereby removal) of catalytic iron from the extracellular space, and in the case of apotransferrin and NGAL, the delivery of iron to viable cells to limit cell death, promote proliferation and enhance recovery. ${ }^{15,19,61,82,83}$ Luminal iron may also reach interstitial macrophages and induce protective mechanisms. ${ }^{49}$ A study of ischaemiareperfusion injury in rats showed that bone-marrowderived macrophages, engineered to overexpress the anti-inflammatory cytokine IL-10, accumulated in damaged kidney tissue. ${ }^{112}$ The infused cells accumulated intracellular iron, which led to iron-dependent upregulation of the expression of NGAL and its receptors NGALR and megalin. ${ }^{12}$ In fact, ischaemia-reperfusion injury in the kidney markedly increased serum, proximal tubule, distal tubule, and urinary levels of NGAL in mice ${ }^{19-21}$ and in humans, ${ }^{19,21}$ and NGAL, in turn, upregulated the expression of HO $1 .{ }^{19}$ Moreover, a high urinary NGAL concentration was associated with an increased risk of post-surgical AKI after cardiopulmonary bypass, an intervention associated with ischaemia in the kidney. This increased risk of post-surgical AKI associated with high urinary NGAL levels is in contrast with the protective effect of intravascular haemolysis in this setting. ${ }^{9}$ However, urinary NGAL levels probably do not reflect the level of local tissue NGAL expression. Another possible explanation for these disparate findings is that the protective effects of NGAL may be counterbalanced by damaging proinflammatory events after cardiopulmonary bypass.

Patients who excrete increased amounts of hepcidin in urine seem to have a low risk of developing AKI after cardiopulmonary bypass. ${ }^{5,8-10}$ This protective effect of hepcidin could be exerted either through increased binding of luminal iron (leading to its urinary excretion) or by increased sequestration of iron within renal tubular epithelial cells (by downregulating the expression of ferroportin on the basolateral membrane) and also in other tissues..$^{8-10}$ Both mechanisms would reduce serum and luminal iron levels, as well as the propagation of tissue damage in the kidney. ${ }^{8-10}$ The source of hepcidin in urine, however, is not completely clear. Increased urinary hepcidin levels might be the result of decreased tubular reabsorption of filtered hepcidin and/or increased local production and secretion of this protein from the kidney tubules. ${ }^{5,6}$ Moreover, increased levels of hepcidin and NGAL in urine could also be innocent bystanders, reflecting other as yet unknown protective mechanisms against kidney injury.

\section{Treatment of iron-related kidney injury}

Iron-induced kidney injury can be prevented or treated by minimizing the reactivity of iron, by removing iron from the kidney or by reducing iron-related oxidative stress. The reactivity of iron can be limited by inducing its incorporation into ferritin. In addition, alkalinization 
of the glomerular filtrate can potentially decrease the rate of iron dissociation from proteins and, therefore, decrease the reactivity of ferryl ( $\mathrm{Fe}^{4+}$-containing) haem proteins; however, a clear benefit from alkalinization in preventing kidney injury has yet to be demonstrated. ${ }^{1}$ Macroscopic haematuria associated with IgA nephropathy can be ameliorated by steroids, owing to their antiinflammatory properties, and these agents are, therefore, a potential treatment for patients with AKI; however, their efficacy needs to be validated in robust clinical trials. ${ }^{16,17}$ Alternatively, iron could be removed from the kidney by blocking its reabsorption in renal tubules. Dogs with decreased expression of cubilin at the apical surface of epithelial cells in the proximal tubules and megalinknockout mice show increased urinary transferrin excretion. ${ }^{113}$ Furthermore, megalin-knockout mice exhibited increased urinary NGAL ${ }^{19}$ and hepcidin ${ }^{114}$ excretion. This increased urinary excretion of transferrin, NGAL and hepcidin suggests increased urinary iron excretion. ${ }^{102,104}$

The calcium channel blocker, nifedipine, increases urinary iron excretion in mice by an unknown mechanism ${ }^{115}$ and decreases iron loading in the kidney in mice and rats fed an iron-enriched diet. ${ }^{115,116}$ Nevertheless, increased urinary iron excretion, which was first shown in mice, has to date not been reproduced either in humans, or animal models of iron overload. ${ }^{116}$ Furthermore, a role for intracellular calcium in mediating these beneficial effects on kidney iron overload has not been reported. To prevent iron reuptake in the renal tubules, conventional iron chelators could potentially be used; however, these agents often cause tubular dysfunction in patients, probably by dramatically decreasing or increasing iron levels in the kidney. ${ }^{117-119}$ Filterable, nonabsorbable iron chelators based on endogenous iron carrier proteins are potentially more suitable for this purpose than chemical ironchelating agents. For example, a patent has been granted for the use of mutant NGAL proteins as novel urinary iron chelators. ${ }^{23}$ Furthermore, basolateral iron export from renal tubular cells could be promoted by inducing upregulation of the expression of basolateral iron exporters ferroportin and FLVCR. Upregulation of the basolateral secretion of ferritin or treatment with a haemopexinbased protein, which could compensate for the diminished circulating haemopexin levels in patients with severe haemolysis, could also decrease iron levels. Iron export via ferroportin and FLVCR may also be induced in interstitial macrophages. Administration of agents that mimic endogenous proteins might enable the kidney to regulate its iron-handling functions and avoid excessive iron mobilization. Finally, treatment with antioxidants might decrease iron-induced tissue injury resulting from oxidative stress.

In practice, successful treatment of iron-induced kidney injury and systemic iron overload depends on a number of factors. The diseases and mechanisms discussed in this Review highlight the variety of causes and complexity of iron-induced kidney injury. In addition, progression of the primary disease that is causing kidney injury might contribute to the observed range of iron-induced injury phenotypes. ${ }^{14}$ Furthermore, multiple independent routes of iron uptake and utilization are thought to exist, the disruption of which might induce various disease phenotypes. ${ }^{53}$ Some treatments, therefore, might not be suitable for specific disease phenotypes, since a change in the supply of iron via a given route might induce unwanted iron overload or depletion via another pathway (for instance, altered cellular iron handling could result in mitochondrial iron overload). Consequently, prevention and treatment of iron-induced kidney injury might require customized iron removal or relocation methods. Detailed knowledge of iron metabolism in the kidney is, therefore, necessary.

Although this Review underlines the potential role of iron in kidney injury, it remains to be proven whether targeting iron levels will offer clinically relevant benefits. Some findings, however, suggest that iron chelation may indeed have clinically relevant effects. Treatment with the divalent metal chelator ethylenediaminetetraacetic acid (EDTA) improved the estimated glomerular filtration rate in patients with chronic renal insufficiency (treated patients experienced an increase of $2.1 \mathrm{ml} / \mathrm{min} / 1.73 \mathrm{~m}^{2}$ versus a decline of $6.1 \mathrm{ml} / \mathrm{min} / 1.73 \mathrm{~m}^{2}$ in nontreated patients), ${ }^{85}$ an effect other researchers attributed to iron chelation. ${ }^{3}$ In another study, administration of the iron chelator, deferiprone, was associated with a $47 \%$ reduction in proteinuria (a decrease from 4.0 to $2.2 \mathrm{~g}$ per day in patients with nondiabetic glomerular nephropathy), and an even more striking reduction in albuminuria (from $187 \mathrm{mg} / \mathrm{g}$ creatinine to $25 \mathrm{mg} / \mathrm{g}$ creatinine) in patients with diabetic nephropathy. ${ }^{24}$ Since proteinuria is the major predictor of progression of kidney disease and any reduction in proteinuria occurs in parallel with a reduction in the rate of decline in glomerular filtration rate, the results of these studies provide an argument for a beneficial effect of iron as a target for therapy.

\section{Conclusions}

In this Review, we have shown that iron has an important role in kidney injury and in the progression of kidney disease. We therefore hypothesize that reducing excessive iron levels in the kidney might contribute to the prevention of ESRD. Improved insights into iron metabolism in the kidney are needed, which requires research to provide leads for the development of novel diagnostic markers, as well as specific, localized and effective therapeutic approaches for the prevention and treatment of iron-induced kidney injury.

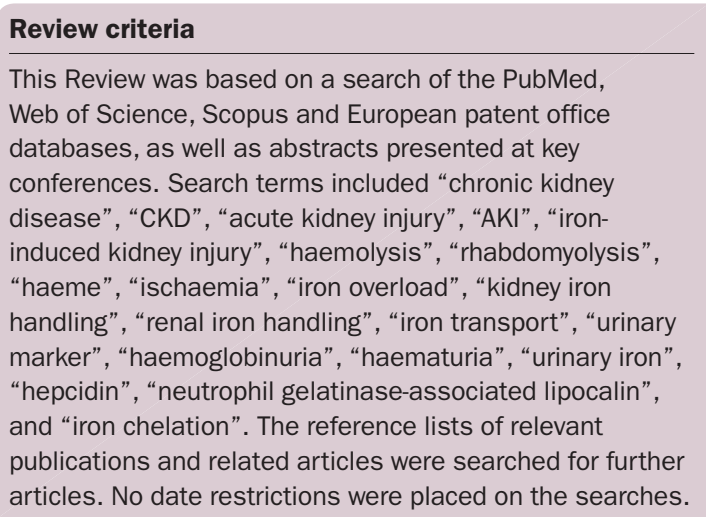


1. Al-Ismaili, Z., Piccioni, M. \& Zappitelli, M. Rhabdomyolysis: pathogenesis of renal injury and management. Pediatr. Nephrol. 26, 1781-1788 (2011).

2. Hentze, M. W., Muckenthaler, M. U., Galy, B. \& Camaschella, C. Two to tango: regulation of mammalian iron metabolism. Cell 142, 24-38 (2010).

3. Shah, S. V., Baliga, R., Rajapurkar, M. \& Fonseca, V. A. Oxidants in chronic kidney disease. J. Am. Soc. Nephrol. 18, 16-28 (2007).

4. Kell, D. B. Iron behaving badly: inappropriate iron chelation as a major contributor to the aetiology of vascular and other progressive inflammatory and degenerative diseases. BMC Med. Genomics 2, 2 (2009).

5. Kroot, J. J. C., Tjalsma, H., Fleming, R. E. \& Swinkels, D. W. Hepcidin in human iron disorders: diagnostic implications. Clin. Chem. 57, 1650-1669 (2011).

6. Veuthey, T., D'Anna, M. C. \& Roque, M. E. Role of the kidney in iron homeostasis: renal expression of prohepcidin, ferroportin, and DMT1 in anemic mice. Am. J. Physiol. Renal Physiol. 295, F1213-F1221 (2008).

7. Haase, M., Mertens, P. R. \& Haase-Fielitz, A. Renal stress in vivo in real-time-visualised by the NGAL reporter mouse. Nephrol. Dial. Transplant. 26, 2109-2111 (2011).

8. Haase-Fielitz, A. et al. Urine hepcidin has additive value in ruling out cardiopulmonary bypassassociated acute kidney injury: an observational cohort study. Crit. Care 15, R186 (2011).

9. Ho, J. et al. mass spectrometry-based proteomic analysis of urine in acute kidney injury following cardiopulmonary bypass: a nested case-control study. Am. J. Kidney Dis. 53, 584-595 (2009).

10. Ho, J. et al. Urinary hepcidin-25 and risk of acute kidney injury following cardiopulmonary bypass. Clin. J. Am. Nephrol. 6, 2340-2346 (2011).

11. Smith, C. P. \& Thévenod, F. Iron transport and the kidney. Biochim. Biophys. Acta 1790, 724-730 (2009).

12. Brittenham, G. M. Iron-chelating therapy for transfusional iron overload. N. Engl. J. Med. 364, 146-156 (2011).

13. Swinkels, D. W., Janssen, M. C. H., Bergmans, J. \& Marx, J. J. M. Hereditary hemochromatosis: genetic complexity and new diagnostic approaches. Clin. Chem. 52, 950-968 (2006).

14. Alfrey, A. C. \& Hammond, W. S. Renal iron handling in the nephrotic syndrome. Kidney Int 37, 1409-1413 (1990).

15. Paller, M. S. \& Hedlund, B. O. Role of iron in postischemic renal injury in the rat. Kidney Int. 34, 474-480 (1988).

16. Moreno, J. A. et al. Haematuria: the forgotten CKD factor? Nephrol. Dial. Transplant. 27, 28-34 (2012).

17. Moreno, J. A. et al. Akl associated with macroscopic glomerular hematuria: clinical and pathophysiologic consequences. Clin. J. Am. Soc. Nephrol. 7, 175-184 (2012).

18. Garrick, M. D. \& Garrick, L. M. Cellular iron transport. Biochim. Biophys. Acta 1790, 309-325 (2009).

19. Mori, K. et al. Endocytic delivery of lipocalin-siderophore-iron complex rescues the kidney from ischemia-reperfusion injury. J. Clin. Invest. 115, 610-621 (2005).

20. Paragas, N. et al. NGAL-siderocalin in kidney disease. Biochim. Biophys. Acta 1823, 1451-1458 (2012).

21. Chakraborty, S., Kaur, S., Guha, S. \& Batra, S. K. The multifaceted roles of neutrophil gelatinase associated lipocalin (NGAL) in inflammation and cancer. Biochim. Biophys. Acta 1826, 129-169 (2012).
22. Pawar, R. D. et al. Neutrophil gelatinaseassociated lipocalin is instrumental in the pathogenesis of antibody-mediated nephritis in mice. Arthritis Rheum. 64, 1620-1631 (2012).

23. Barasch, J. \& Qiu, A. Mutant NGAL proteins and uses thereof. International patent application WO/2011/149962 (2011).

24. Rajapurkar, M. M., Hegde, U., Bhattacharya, A. Alam, M. G. \& Shah, S. V. Effect of deferiprone, an oral iron chelator, in diabetic and non-diabetic glomerular disease. Toxicol. Mech. Methods 23, 5-10 (2013).

25. Goraya, N., Simoni, J., Jo, C. \& Wesson, D. E. Dietary acid reduction with fruits and vegetables or bicarbonate attenuates kidney injury in patients with a moderately reduced glomerular filtration rate due to hypertensive nephropathy. Kidney Int. 81, 86-93 (2012).

26. Zhang, D., Meyron-Holtz, E. \& Rouault, T. A. Renal iron metabolism: transferrin iron delivery and the role of iron regulatory proteins. J. Am. Soc. Nephrol. 18, 401-406 (2007).

27. García-Montoya, I. A., Cendón, T. S., Arévalo-Gallegos, S. \& Rascón-Cruz, Q. Lactoferrin a multiple bioactive protein: an overview. Biochim. Biophys. Acta 1820, 226-236 (2012).

28. Adlerova, L., Bartoskova, A. \& Faldyna, M. Lactoferrin: a review. Vet. Med. (Praha). 53, 457-468 (2008).

29. Åbrink, M., Larsson, E., Gobl, A. \& Hellman, L. Expression of lactoferrin in the kidney: Implications for innate immunity and iron metabolism. Kidney Int. 57, 2004-2010 (2000).

30. Norden, A. G. W. et al. Glomerular protein sieving and implications for renal failure in Fanconi syndrome. Kidney Int. 60, 1885-1892 (2001).

31. Itzhaki, R. F. \& Belcher, E. H. Studies on plasma iron in the rat. II. Plasma iron concentration and plasma iron-binding capacity. Arch. Biochem. Biophys. 92, 74-80 (1961).

32. Tanner, G. A. Glomerular sieving coefficient of serum albumin in the rat: a two-photon microscopy study. Am. J. Physiol. Renal Physiol. 296, F1258-F1265 (2009).

33. Cohen, L. A. et al. Serum ferritin is derived primarily from macrophages through a nonclassical secretory pathway. Blood 116 , 1574-1584 (2010).

34. Marzolo, M. P. \& Farfán, P. New insights into the roles of megalin/LRP2 and the regulation of its functional expression. Biol. Res. 44, 89-105 (2011).

35. Le Blanc, S., Garrick, M. D. \& Arredondo, M. Heme carrier protein 1 transports heme and is involved in heme-Fe metabolism. Am. J. Physiol Cell Physiol. 302, C1780-C1785 (2012).

36. Nath, K. A. Heme oxygenase-1: a provenance for cytoprotective pathways in the kidney and other tissues. Kidney Int. 70, 432-443 (2006).

37. Zarjou, A. et al. proximal tubule $\mathrm{H}$-ferritin mediates renal iron trafficking and confers protection in acute kidney injury. J. Am. Soc. Nephrol. 23, 96A (2012).

38. Langelueddecke, C. et al. Lipocalin-2 (24p3/ neutrophil gelatinase-associated lipocalin (NGAL)) receptor is expressed in distal nephron and mediates protein endocytosis. J. Biol. Chem. 287, 159-169 (2012).

39. Khan, A. A. \& Quigley, J. G. Control of intracellular heme levels: heme transporters and heme oxygenases. Biochim. Biophys. Acta 1813, 668-682 (2011).

40. Cheng, X., Shen, D., Samie, M. \& Xu, H. Mucolipins: intracellular TRPML1-3 channels. FEBS Lett. 584, 2013-2021 (2010).

41. Jenkitkasemwong, S., Wang, C. Y., Mackenzie, B. $\&$ Knutson, M. D. Physiologic implications of metal-ion transport by ZIP14 and ZIP8. Biometals 25, 643-655 (2012)

42. Yanatori, I. et al. Heme and non-heme iron transporters in non-polarized and polarized cells BMC Cell Biol. 11, 39 (2010).

43. Vesey, D. A. Transport pathways for cadmium in the intestine and kidney proximal tubule: focus on the interaction with essential metals. Toxicol. Lett. 198, 13-19 (2010).

44. Wolff, N. A. et al. Ferroportin 1 is expressed basolaterally in rat kidney proximal tubule cells and iron excess increases its membrane trafficking. J. Cell. Mol. Med. 15, 209-219 (2011).

45. Yang, Z. et al. Kinetics and specificity of feline leukemia virus subgroup $C$ receptor (FLVCR) export function and its dependence on hemopexin. J. Biol. Chem. 285, 28874-28882 (2010).

46. Camborieux, L., Julia, V., Pipy, B. \& Swerts, J. P. Respective roles of inflammation and axonal breakdown in the regulation of peripheral nerve hemopexin: an analysis in rats and in C57BL/ Wids mice. J. Neuroimmunol. 107, 29-41 (2000).

47. Tolosano, E., Fagoonee, S., Morello, N., Vinchi, F. \& Fiorito, V. Heme scavenging and the other facets of hemopexin. Antioxid. Redox Signal. 12, 305-320 (2010).

48. Moestrup, S. K., Gliemann, J. \& Pallesen, G. Distribution of the a2-macroglobulin receptor/ low density lipoprotein receptor-related protein in human tissues. Cell Tissue Res. 269, 375-382 (1992).

49. Zager, R. A., Vijayan, A. \& Johnson, A. C. M. Proximal tubule haptoglobin gene activation is an integral component of the acute kidney injury "stress response". Am. J. Physiol. Renal Physiol. 303, F139-F148 (2012).

50. Van Gorp, H., Delputte, P. L. \& Nauwynck, H. J. Scavenger receptor CD163, a Jack-of-all-trades and potential target for cell-directed therapy. Mol. Immunol. 47, 1650-1660 (2010).

51. Sponsel, H. T. et al. Effect of iron on renal tubular epithelial cells. Kidney Int. 50, 436-444 (1996).

52. Sheerin, N. S., Sacks, S. H. \& Fogazzi, G. B. In vitro erythrophagocytosis by renal tubular cells and tubular toxicity by haemoglobin and iron. Nephrol. Dial. Transplant. 14, 1391-1397 (1999).

53. Shvartsman, M. \& Cabantchik, Z. I. Intracellular iron trafficking: role of cytosolic ligands. Biometals 25, 711-723 (2012).

54. Philpott, C. C. Coming into view: eukaryotic iron chaperones and intracellular iron delivery. J. Biol. Chem. 287, 13518-13523 (2012).

55. Johnson, A. C. M., Becker, K. \& Zager, R. A Parenteral iron formulations differentially affect MCP-1, HO-1, and NGAL gene expression and renal responses to injury. Am. J. Physiol. Renal Physiol 299, F426-F435 (2010).

56. Ludwiczek, S., Theurl, I., Bahram, S., Schümann, K. \& Weiss, G. Regulatory networks for the control of body iron homeostasis and their dysregulation in HFE mediated hemochromatosis. J. Cell. Physiol. 204, 489-499 (2005).

57. Liu, Q. S., Nilsen-Hamilton, M. \& Xiong, S. D. Synergistic regulation of the acute phase protein SIP24/24p3 by glucocorticoid and proinflammatory cytokines. Acta Physiologica Sinica 55, 525-529 (2003).

58. Roudkenar, M. H. et al. Oxidative stress induced lipocalin 2 gene expression: addressing its expression under the harmful conditions. J. Radiat. Res. 48, 39-44 (2007).

59. Roudkenar, M. H. et al. Upregulation of neutrophil gelatinase-associated lipocalin, 
NGAL/Lcn2, in $\beta$-thalassemia patients. Arch. Med. Res. 39, 402-407 (2008)

60. Zager, R. A. \& Burkhart, K. Myoglobin toxicity in proximal human kidney cells: roles of $\mathrm{Fe}, \mathrm{Ca}^{2+}$, $\mathrm{H}_{2} \mathrm{O}_{2}$, and terminal mitochondrial electron transport. Kidney Int. 51, 728-738 (1997).

61. Paller, M. S. \& Hedlund, B. E. Extracellular iron chelators protect kidney cells from hypoxia/ reoxygenation. Free Radic. Biol. Med. 17, 597-603 (1994).

62. Kovtunovych, G., Eckhaus, M. A., Ghosh, M. C., Ollivierre-Wilson, H. \& Rouault, T. A. Dysfunction of the heme recycling system in heme oxygenase 1-deficient mice: effects on macrophage viability and tissue iron distribution. Blood 116, 6054-6062 (2010).

63. Hashemieh, M., Azarkeivan, A., Akhlaghpoor, S., Shirkavand, A. \& Sheibani, K. T2-star (T2*) magnetic resonance imaging for assessment of kidney iron overload in thalassemic patients. Arch. Iranian Med. 15, 91-94 (2012).

64. Sears, D. A., Anderson, P. R., Foy, A. L. Williams, H. L. \& Crosby, W. H. Urinary iron excretion and renal metabolism of hemoglobin in hemolytic diseases. Blood 28, 708-725 (1966).

65. Schein, A., Enriquez, C., Coates, T. D. \& Wood, J. C. Magnetic resonance detection of kidney iron deposition in sickle cell disease: a marker of chronic hemolysis. J. Magn. Reson. Imaging 28, 698-704 (2008).

66. Ballarín, J. et al. Acute renal failure associated to paroxysmal nocturnal haemoglobinuria leads to intratubular haemosiderin accumulation and CD163 expression. Nephrol. Dial. Transplant. 26, 3408-3411 (2011).

67. Fervenza, F. C. et al. Induction of heme oxygenase- 1 and ferritin in the kidney in warm antibody hemolytic anemia. Am. J. Kidney Dis. 52, 972-977 (2008).

68. Rakow-Penner, R., Glader, B., Yu, H. \& Vasanawala, S. Adrenal and renal corticomedullary junction iron deposition in red cell aplasia. Pediatr. Radiol. 40, 1955-1957 (2010).

69. Rous, P. Urinary siderosis: hemosiderin granules in the urine as an aid in the diagnosis of pernicious anemia, hemochromatosis, and other diseases causing siderosis of the kidney. J. Exp. Med. 28, 645-658 (1918).

70. Wang, H. et al. Iron deposition in renal biopsy specimens from patients with kidney diseases. Am. J. Kidney Dis. 38, 1038-1044 (2001).

71. Ueda, N., Baliga, R. \& Shah, S. V. Role of 'catalytic' iron in an animal model of minimal change nephrotic syndrome. Kidney Int. 49 , 370-373 (1996)

72. Zager, R. A., Foerder, C. \& Bredl, C. The influence of mannitol on myoglobinuric acute renal failure: functional, biochemical, and morphological assessments. J. Am. Soc. Nephrol. 2, 848-855 (1991).

73. Delaby, C. et al. Renal handling of iron in mouse models of iron overload: recent concept. Am. J. Hematol. 86, E42 (2011).

74. Baliga, R., Zhang, Z., Baliga, M. \& Shah, S. V. Evidence for cytochrome P-450 as a source of catalytic iron in myoglobinuric acute renal failure. Kidney Int. 49, 362-369 (1996).

75. Gutiérrez, L., Vujic Spasic, M., Muckenthaler, M. U. \& Lázaro, F. J. Quantitative magnetic analysis reveals ferritin-like iron as the most predominant iron-containing species in the murine Hfe-haemochromatosis. Biochim. Biophys. Acta 1822, 1147-1153 (2012).

76. Harris, D. C. H. \& Tay, Y. C. Mitochondrial function in rat renal cortex in response to proteinuria and iron. Clin. Exp. Pharmacol. Physiol. 24, 916-922 (1997).
77. Harris, D. C. H., Tay, C. \& Nankivell, B. J. Lysosomal iron accumulation and tubular damage in rat puromycin nephrosis and ageing. Clin. Exp. Pharmacol. Physiol. 21, 73-81 (1994)

78. Nankivell, B. J. \& Harris, D. C. H. Iron depletion in the remnant kidney. Nephron 70, 340-347 (1995).

79. Nankivell, B. J., Chen, J., Boadle, R. A. \& Harris, D. C. H. The role of tubular iron accumulation in the remnant kidney. J. Am. Soc. Nephrol. 4, 1598-1607 (1993).

80. Viau, A. et al. Lipocalin 2 is essential for chronic kidney disease progression in mice and humans. J. Clin. Invest. 120, 4065-4076 (2010).

81. Remuzzi, A., Puntorieri, S., Brugnetti, B., Bertani, T. \& Remuzzi, G. Renoprotective effect of low iron diet and its consequence on glomerular hemodynamics. Kidney Int. 39, 647-652 (1991).

82. De Vries, B. et al. Reduction of circulating redoxactive iron by apotransferrin protects against renal ischemia-reperfusion injury. Transplantation 77, 669-675 (2004).

83. Mishra, J. et al. Amelioration of ischemic acute renal injury by neutrophil gelatinase-associated lipocalin. J. Am. Soc. Nephrol. 15, 3073-3082 (2004).

84. Michelakakis, H. et al. Iron overload and urinary lysosomal enzyme levels in $\beta$-thalassaemia major. Eur. J. Pediatr. 156, 602-604 (1997).

85. Lin, J. L., Lin-Tan, D. T., Hsu, K. H. \& Yu, C. C. Environmental lead exposure and progression of chronic renal diseases in patients without diabetes. N. Engl. J. Med. 348, 277-286 (2003).

86. Aldudak, B. et al. Renal function in pediatric patients with $\beta$-thalassemia major. Pediatr. Nephrol. 15, 109-112 (2000).

87. Koliakos, G. et al. Urine biochemical markers of early renal dysfunction are associated with iron overload in $\beta$-thalassaemia. Clin. Lab. Haematol. 25, 105-109 (2003).

88. Nath, K. A. et al. Heme protein-induced chronic renal inflammation: suppressive effect of induced heme oxygenase-11. Kidney Int. 59, 106-117 (2001).

89. Boutaud, O. \& Roberts II, L. J. Mechanism-based therapeutic approaches to rhabdomyolysisinduced renal failure. Free Radic. Biol. Med. 51 1062-1067 (2011)

90. Hsiao, P. J., Wang, S. C., Wen, M. C., Diang, L. K. \& Lin, S. H. Fanconi syndrome and CKD in a patient with paroxysmal nocturnal hemoglobinuria and hemosiderosis. Am. J. Kidney Dis. 55, e1-e5 (2010).

91. Leonardi, P. \& Ruol, A. Renal hemosiderosis in the hemolytic anemias: diagnosis by means of needle biopsy. Blood 16, 1029-1038 (1960).

92. Zager, R. A. Rhabdomyolysis and myohemoglobinuric acute renal failure. Kidney Int. 49, 314-326 (1996)

93. Zager, R. A., Johnson, A. C. M. \& Becker, K Renal cortical hemopexin accumulation in response to acute kidney injury. Am. J. Physiol. Renal Physiol. 303, F1460-F1472 (2012).

94. Tolosano, E. et al. Haptoglobin modifies the hemochromatosis phenotype in mice. Blood 105, 3353-3355 (2005).

95. Zhou, X. Y. et al. HFE gene knockout produces mouse model of hereditary hemochromatosis. Proc. Natl Acad. Sci. USA 95, 2492-2497 (1998).

96. Muncie, J. \& Campbell, J. S. Alpha and beta thalassemia. Am. Fam. Physician 80, 339-344 (2009).

97. Amer, J., Goldfarb, A. \& Fibach, E. Flow cytometric analysis of the oxidative status of normal and thalassemic red blood cells. Cytometry A 60, 73-80 (2004).
98. Chiou, S. S. et al. Lipid peroxidation and antioxidative status in $\beta$-thalassemia major patients with or without hepatitis $\mathrm{C}$ virus infection. Clin. Chem. Lab. Med. 44, 1226-1233 (2006).

99. Livrea, M. A. et al. Oxidative stress and antioxidant status in $\beta$-thalassemia major: iron overload and depletion of lipid-soluble antioxidants. Blood 88, 3608-3614 (1996).

100. Walter, P. B. et al. Oxidative stress and inflammation in iron-overloaded patients with $\beta$-thalassaemia or sickle cell disease. Br. J. Haematol. 135, 254-263 (2006).

101. Mackinnon, B. et al. Urinary transferrin, high molecular weight proteinuria and the progression of renal disease. Clin. Nephrol. 59, 252-258 (2003).

102. Brown, E. A., Sampson, B., Muller, B. R. \& Curtis, J. R. Urinary iron loss in the nephrotic syndrome-an unusual cause of iron deficiency with a note on urinary copper losses. Postgrad. Med. J. 60, 125-128 (1984).

103. Howard, R. L., Buddington, B. \& Alfrey, A. C. Urinary albumin, transferrin and iron excretion in diabetic patients. Kidney Int. 40, 923-926 (1991).

104. Prinsen, B. H. C. M. et al. Transferrin synthesis is increased in nephrotic patients insufficiently to replace urinary losses. J. Am. Soc. Nephrol. 12, 1017-1025 (2001).

105. Ellis, D. Anemia in the course of the nephrotic syndrome secondary to transferrin depletion. J. Pediatr. 90, 953-955 (1977).

106. Naito, Y. et al. Effect of iron restriction on renal damage and mineralocorticoid receptor signaling in a rat model of chronic kidney disease. J. Hypertens. 30, 2192-2201 (2012).

107. Mahmoodi, B. K. et al. Associations of kidney disease measures with mortality and end-stage renal disease in individuals with and without hypertension: a meta-analysis. Lancet $\mathbf{3 8 0}$, 1649-1661 (2012).

108. Gutierrez, E. et al. Oxidative stress, macrophage infiltration and CD163 expression are determinants of long-term renal outcome in macrohematuria-induced acute kidney injury of IgA nephropathy. Nephron Clin. Pract. 121, C42-C53 (2012)

109. Eller, K., Banas, M. C., Kirsch, A. H. \& Rosenkranz, A. R. Lipocalin-2 is an endogenous inhibitor of inflammation in murine nephrotoxic serum nephritis. J. Am. Soc. Nephrol. 23, 563A (2012)

110. Lipton, P. Ischemic cell death in brain neurons. Physiol. Rev. 79, 1431-1568 (1999).

111. Sola, A., Ventayol, A. \& Hotter, G. Lcn-2 overexpressing bone marrow-derived macrophages promote renal regeneration. J.Am. Soc. Nephrol. 23, 106A (2012)

112. Jung, M. et al. Infusion of IL-10-expressing cells protects against renal ischemia through induction of lipocalin-2. Kidney Int. 81, 969-982 (2012)

113. Kozyraki, R. et al. Megalin-dependent cubilinmediated endocytosis is a major pathway for the apical uptake of transferrin in polarized epithelia. Proc. Natl Acad. Sci. USA 98 12491-12496 (2001).

114. Peters, H. P. E. et al. Tubular reabsorption and local production of urine hepcidin-25. BMC Nephrology 14, 70 (2013).

115. Ludwiczek, S. et al. $\mathrm{Ca}^{2+}$ channel blockers reverse iron overload by a new mechanism via divalent metal transporter-1. Nat. Med. 13, 448-454 (2007)

116. Liu, C. B., Wu, B., Xiao, M. \& Wang, L. Q. Effects of nifedipine on iron deposits and nutritional metabolism in chronic iron-overloaded rats. Chinese J. Pharmacol. Toxicol. 25, 77-82 (2011). 


\section{REVIEWS}

117. Huang, X.P., Thiessen, J. J., Spino, M. \& Templeton, D. M. Transport of iron chelators and chelates across MDCK cell monolayers: Implications for iron excretion during chelation therapy. Int. J. Hematol. 91, 401-412 (2010).

118. Abbas, M. et al. Evaluation of urinary excretion and renal clearance of deferiprone, creatinine, iron and zinc in human. Asian J. Chem. 6 , 4583-4592 (2009).

119. Baum, M. Renal Fanconi syndrome secondary to deferasirox: where there is smoke there is fire. J. Pediatr. Hematol. Oncol. 32, 525-526 (2010).

120. Suzuki, Y. A. \& Lönnerdal, B. Baculovirus expression of mouse lactoferrin receptor and tissue distribution in the mouse. Biometals 17, 301-309 (2004).

121. Zhao, R., Diop-Bove, N., Visentin, M. \& Goldman, I. D. Mechanisms of membrane transport of folates into cells and across epithelia. Annu. Rev. Nutr. 31, 177-201 (2011).

122. Shepard, M., Dhulipala, P., Kabaria, S. Abraham, N. G. \& Lianos, E. A. Heme oxygenase-1 localization in the rat nephron. Nephron 92, 660-664 (2002).

123. Branten, A. J. W., Swinkels, D. W., Klasen, I. S. \& Wetzels, J. F. M. Serum ferritin levels are increased in patients with glomerular diseases and proteinuria. Nephrol. Dial. Transplant. 19, 2754-2760 (2004).

124. Paragas, N. et al. The Ngal reporter mouse detects the response of the kidney to injury in real time. Nat. Med. 17, 216-223 (2011).

125. Haase, V. H. Hemoglobin in the kidney: breaking with traditional dogma. J. Am. Soc. Nephrol. 19, 1440-1441 (2008).

126. Rodríguez-Capote, K. et al. Utility of urine myoglobin for the prediction of acute renal failure in patients with suspected rhabdomyolysis: a systematic review. Clin. Chem. 55, 2190-2197 (2009).

127. Kulaksiz, H. et al. The iron-regulatory peptide hormone hepcidin: expression and cellular localization in the mammalian kidney. J. Endocrinol. 184, 361-370 (2005).
128. Kapojos, J. J. et al. Production of hemopexin by TNF-a stimulated human mesangial cells. Kidney Int. 63, 1681-1686 (2003).

129. Baliga, R., Ueda, N. \& Shah, S. V. Increase in bleomycin-detectable iron in ischaemia/ reperfusion injury to rat kidneys. Biochem. J. 291, 901-905 (1993).

\section{Acknowledgements}

The authors' research work is partly funded by an Innovation grant from the Dutch Kidney foundation (to R. Masereeuw, J. F. M. Wetzels and D. W. Swinkels; project number IP 12.81).

\section{Author contributions}

A. M. F. Martines researched data for the article and wrote the manuscript. A. M. F. Martines,

R. Masereeuw, H. Tjalsma, J. G. Hoenderop,

J. F. M. Wetzels and D. W. Swinkels contributed substantially to discussions of the content and/or editing of the manuscript before submission.

Supplementary information is linked to the online version of the paper at www.nature.com/nrnephrol 